\title{
Reports of Original Investigations
}

\section{Laryngeal injuries and intubating conditions with or without muscular relaxation: an equivalence study}

\section{[Lésions laryngées et conditions d'intubation avec ou sans relaxation musculaire :} une étude d'équivalence]

Lionel Bouvet MD, ${ }^{*}$ Alina Stoian MD, ${ }^{*}$ Sophie Jacquot-Laperrière MD, $\dagger$ Bernard Allaouchiche MD PhD, * Dominique Chassard MD PhD, ${ }^{*}$ Emmanuel Boselli MD PhD*

\begin{abstract}
Purpose: The need for muscular relaxation to improve intubating conditions and to reduce the incidence of laryngeal morbidity is still controversial. The aim of this study was to determine the incidence of symptomatic laryngeal injuries (SLI) and of acceptable intubating conditions (including both good and excellent conditions), both with and without cisatracurium during induction of anesthesia, along with moderate doses of remifentanil and propofol.
\end{abstract}

Methods: In this prospective, randomized double-blind equivalence trial, the intubating conditions were compared in 130 ASA I or II female patients. All subjects received remifentanil $2 \mu \mathrm{g} \cdot \mathrm{kg}^{-1}$ iv and propofol $2.5 \mathrm{mg} \cdot \mathrm{kg}^{-1}$ iv, with either cisatracurium $0.15 \mathrm{mg} \cdot \mathrm{kg}^{-1}$ iv (group Cisatracturium), or saline (group Placebo). Tracheal intubating conditions were assessed with the Copenhagen Score. A systematic screening for postoperative hoarseness and sore throat was performed 24 and $48 \mathrm{hr}$ after anesthesia, followed by a nasofibroscopic examination when laryngeal symptoms persisted at $48 \mathrm{hr}$.

Results: Twenty-four hr after anesthesia, the incidence of postoperative hoarseness and sore throat in the Cisatracurium and Placebo groups was $26.5 \%$ and $21.5 \%$, respectively, and $48 \mathrm{hr}$ after anesthesia, the incidence was $7.8 \%$ and $6.1 \%$, respectively ( $P=0.32$ and $P=0.50$ between groups, respectively). In the clinically evaluable population, the incidence of SLI, assessed at $48 \mathrm{hr}$ by nasofibroscopy, was equivalent in both groups, $1.6 \%$ vs $1.5 \%$ in group Placebo and group Cisatracurium, respectively $(P<0.00$ I for equivalence test $)$, as was the occurrence of acceptable intubating conditions $(95.4 \%$ vs $100 \%, P<0.05$ for equivalence test). However, the occurrence of excellent intubating conditions was more frequent in group Cisatracurium than in group Placebo $(P=0.0003)$.

Conclusion: Following induction of anesthesia with propofol and moderate-dose remifentanil, cisatracurium did not confer a higher rate of good-to-excellent conditions for tracheal intubation, nor did muscle relaxation with cisatracurium decrease the rate of SLI after tracheal intubation.

CAN J ANESTH 2008/ 55: 10/pp 674-684

Objectif : Le besoin de relaxation musculaire dans le but d'améliorer les conditions d'intubation et de réduire l'incidence de morbidité laryngée demeure controversé. L'objectif de cette étude était de déterminer l'incidence de lésions laryngées symptomatiques et des conditions d'intubation acceptables (incluant les conditions bonnes et excellentes), avec ou sans cisatracurium pendant l'induction de l'anesthésie, et combiné à des doses modérées de rémifentanil et de propofol.

Méthode : Dans cette étude d'équivalence prospective, randomisée et à double insu, les conditions d'intubation ont été comparées chez 130 patientes ASA I ou II. Toutes les patientes ont reçu $2 \mu \mathrm{g} \cdot \mathrm{kg}^{-1} \mathrm{de}$ rémifentanil iv et $2.5 \mathrm{mg} \cdot \mathrm{kg}^{-1}$ de propofol iv, avec soit $0,15 \mathrm{mg} \cdot \mathrm{kg}^{-1}$ de cisatracurium iv (groupe Cisatracurium), soit une solution saline

From the Departments of Anesthesia and Intensive Care, ${ }^{*}$ and Ear, Nose, and Throat Surgery, $†$ Édouard Herriot Hospital, and Claude Bernard Lyon 1 University of Lyon, Lyon, France.

Address correspondence to: Dr. Lionel Bouvet, Department of Anesthesia and Intensive Care, Édouard Herriot Hospital, place

d'Arsonval, Lyon 69003, France. Phone: + 334724131 72; Fax: + 3347241 31 35; E-mail: lionel.bouvet@chu-lyon.fr

Financial support for this study was provided solely from institutional sources.

Conflicts of interest: None declared.

Accepted for publication June 26, 2008.

This article is accompanied by an editorial. Please see Can J Anesth 2008; 55: 663-9. 
(groupe Placebo). Les conditions d'intubation trachéale ont été évaluées à l'aide de l'échelle de Copenhague. Un dépistage systématique de l'enrouement et des maux de gorge postopératoires a été réalisé 24 et 48 h après l'anesthésie, suivi d'un examen nasofibroscopique lorsque les symptômes laryngés persistaient à $48 \mathrm{~h}$.

Résultats: L'incidence d'enrouement et de maux de gorge postopératoires à $24 \mathrm{~h}$ était de $26,5 \%$ et $21,5 \%$ dans les groupes Cisatracurium et Placebo, respectivement. Quarante-huit heures après l'anesthésie, l'incidence était de 7,8 \% et $6,1 \%$, respectivement $(P=0,32$ et $P=0,50$ entre les groupes, respectivement). Dans la population évaluable cliniquement, l'incidence de lésions laryngées symptomatiques, évaluée à $48 \mathrm{~h}$ par nasofibroscopie, était équivalente dans les deux groupes, soit I,6\% et I,5\% dans le groupe Placebo et le groupe Cisatracurium, respectivement ( $P<0,00$ l pour le test d'équivalence), tout comme l'occurrence avec des conditions d'intubation acceptable $(95,4 \%$ vs $100 \%$, $P<0,05$ pour le test d'équivalence). Toutefois, l'occurrence dans les situations où les conditions d'intubation étaient excellentes était plus fréquente dans le groupe Cisatracurium que dans le groupe Placebo $(P=0,0003)$.

Conclusion : À la suite d'une induction de l'anesthésie à l'aide de propofol et de rémifentanil en dose modérée, le cisatracurium n'a pas procuré un taux plus élevé de conditions bonnes à excellentes pour l'intubation trachéale ; en outre, la relaxation musculaire procurée par le cisatracurium n'a pas non plus réduit le taux de lésions laryngées symptomatiques après l'intubation trachéale.

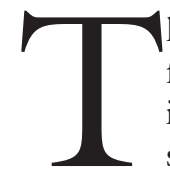

he quality of intubating conditions, as a risk factor for laryngeal injury during tracheal intubation, remains controversial. Whereas some authors report similar frequencies of laryngeal morbidity in patients with either excellent or good intubating conditions, ${ }^{1-4}$ others have shown that excellent intubating conditions, provided by the administration of neuromuscular blocking drugs (NMBDs) at induction of anesthesia, are associated with fewer postoperative laryngeal symptoms and less tissue damage than are associated with non-excellent conditions. ${ }^{5,6}$ Hence, optimizing intubating conditions by using NMBDs would be required to minimize airway symptoms and injuries related to tracheal intubation. ${ }^{5,6}$

However, patient factors may contraindicate the use of NMBDs, and administration of NMBDs may be associated with several potentially serious complications, such as anaphylactic reactions, residual curarization (even after a single intubating dose of NMBD), and awareness during general anesthesia. ${ }^{7-9}$ Moreover, high rates of good to excellent intubat- ing conditions have been reported without the use of NMBDs, provided that the anesthetic induction protocol is optimized with an adequate dose of an opioid analgesic co-administered with either propofol or thiopental. ${ }^{10-16}$ Due to its rapid onset, remifentanil $2 \mu \mathrm{g} \cdot \mathrm{kg}^{-1}$, combined with propofol $2 \mathrm{mg} \cdot \mathrm{kg}^{-1}$, provides acceptable intubating conditions in 75 to $85 \%$ of patients. ${ }^{11,12}$ However, no previous study has evaluated potential laryngeal morbidity associated with an optimized relaxant-free anesthetic induction protocol. Therefore, we conducted a prospective, double-blind equivalence study to determine the incidence of symptomatic laryngeal injuries (SLI) and the rate of acceptable intubating conditions associated with anesthetic induction, either with or without muscle relaxation, using cisatracurium at induction of anesthesia.

\section{Methods}

Patients

Following approval of the study protocol from the Hospital Ethics Committee and after obtaining written informed consent from the patients, adult female subjects, scheduled for elective gynecological surgery, were enrolled in this prospective, randomized doubleblind study. All subjects were ASA physical status class I or II with age $>$ than $18 \mathrm{yr}$. Only those surgeries deemed to require tracheal intubation, without the use of NMBDs and with an anticipated duration > one hour, were considered. Patients excluded from the study were those with either a history or evidence of a difficult airway (combination of the Mallampati score 3 or 4 , thyromental distance $<60 \mathrm{~mm},{ }^{17}$ mouth opening $<35 \mathrm{~mm}$ ) or with any contraindication to the use of NMBDs.

\section{Anesthesia protocol}

The anesthesia protocol is summarized in Figure 1. Premedication was prescribed at the discretion of the attending anesthesiologist, according to the patient's anxiety. When appropriate, alprazolam $0.5 \mathrm{mg}$ and/or hydroxyzine 0.5 to $2 \mathrm{mg} \cdot \mathrm{kg}^{-1}$ were administered po one hour before induction of anesthesia.

Patients were randomized by a computer-generated list to receive either cisatracurium $0.15 \mathrm{mg} \cdot \mathrm{kg}^{-1}$ (group Cisatracurium) or saline (group Placebo) at induction of anesthesia. Allocation concealment was ensured by the use of coded, sealed opaque envelopes. In the operating room, following application of routine monitors, patients were pre-oxygenated until their end-tidal oxygen fraction was $>90 \%$, after which anesthesia was induced. At time $\mathrm{T}_{0}$, remifentanil $2 \mu \mathrm{g} \cdot \mathrm{kg}^{-1}$ iv was infused over $60 \mathrm{sec}$ using a programmable device (Pilote Anesthésie $2{ }^{\circledR}$, Fresenius Vial, 


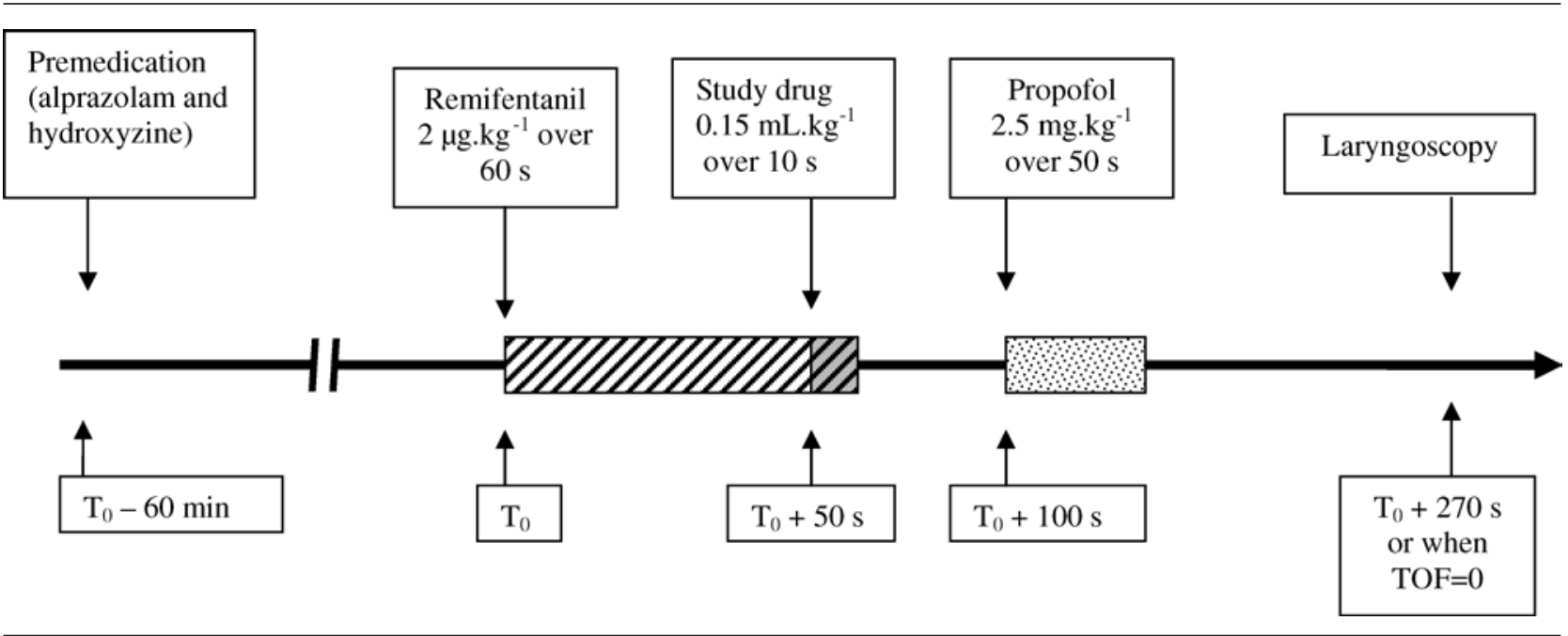

FIGURE 1 Schematic representation of the anesthetic induction sequence. TOF $=$ train of four.

Brezins, France), followed by a continuous infusion of $0.15 \mu \mathrm{g} \cdot \mathrm{kg}^{-1} \cdot \mathrm{min}^{-1}$. At time $\mathrm{T}_{0}+50 \mathrm{sec}$, the study drug $0.15 \mathrm{~mL} \cdot \mathrm{kg}^{-1}$ (cisatracurium $1 \mathrm{mg} \cdot \mathrm{mL}^{-1}$ or saline) was administered intravenously over ten seconds. Next, at $\mathrm{T}_{0}+100 \mathrm{sec}$, propofol $2.5 \mathrm{mg} \cdot \mathrm{kg}^{-1}$ iv was administered over $50 \mathrm{sec}$. Ventilation via facemask was initiated upon loss of the eyelash reflex. If disappearance of the twitch responses (see below) in group Cisatracurium did not occur at $\mathrm{T}_{0}+270 \mathrm{sec}$, continuous infusion of $6 \mathrm{mg} \cdot \mathrm{kg}^{-1} \cdot \mathrm{hr}^{-1}$ propofol was started and then discontinued once the fourth twitch response disappeared.

The same experienced senior physician, blinded to the anesthetic regimen, performed all tracheal intubations using a Macintosh 3 laryngoscope metal blade. At the anesthesiologists' discretion, an endotracheal tube of 6.5 or $7 \mathrm{~mm}$ internal diameter was inserted. At time $\mathrm{T}_{0}+270 \mathrm{sec}$ in group Placebo, or upon disappearance of all four twitches [in response to train-of-four (TOF) stimulation at the adductor pollicis muscle] in group Cisatracurium, the study physician was allowed to enter the operating room to attempt the patient's tracheal intubation. The quality of tracheal intubation was assessed as described further. If intubating conditions were judged to be uncomfortable, or if clinical signs suggestive of inadequate anesthesia (limb movement, cough, tachycardia, increase in systolic blood pressure exceeding $20 \%$ of the preinduction value) were observed, supplemental intravenous boluses of propofol $0.5 \mathrm{mg} \cdot \mathrm{kg}^{-1}$ and/or remifentanil $0.5 \mu \mathrm{g} \cdot \mathrm{kg}^{-1}$ were administered at the discretion of the intubating anesthesiologist who was unaware of the patient's group assignment. No topical anesthesia of the larynx was provided. The tracheal tube cuff was inflated with 5-10 $\mathrm{mL}$ of air, while ensuring that intracuff pressure was $<25 \mathrm{~cm} \mathrm{H}_{2} \mathrm{O}$, and was continuously monitored throughout anesthesia.

Monitors included an automated blood pressure cuff, electrocardiogram, peripheral pulse oximeter, and capnometer. Control values of arterial pressure and heart rate were recorded before induction of anesthesia (preinduction values), at one, three, and five minutes following tracheal intubation. If mean arterial pressure or heart rate decreased by more than $25 \%$, in comparison to corresponding preinduction values, ephedrine $6 \mathrm{mg}$ iv or atropine $0.5 \mathrm{mg} i \mathrm{v}$ was administered. Neuromuscular transmission monitoring was performed using acceleromyography (TOF-Watch ${ }^{\circledR}$, Organon Teknika BV, Boxtel, The Netherlands) on the left hypothenar muscle. Calibration was performed at time $\mathrm{T}_{0}+45 \mathrm{sec}$. After loss of consciousness, TOF stimulations $(50 \mathrm{~mA})$ were applied to the ulnar nerve every ten seconds. The time interval between the end of cisatracurium injection and the disappearance of the four twitch responses at the adductor pollicis muscle defined the onset of action of cisatracurium, allowing the first attempt to intubate the trachea in group Cisatracurium. At the end of surgery, reversal of residual neuromuscular block was achieved with neostigmine $40 \mu \mathrm{g} \cdot \mathrm{kg}^{-1}$, plus atropine $20 \mu \mathrm{g} \cdot \mathrm{kg}^{-1}$, if the TOF ratio was $<1.0 .^{18}$

\section{Assessment of intubating conditions}

The quality of tracheal intubation was assessed using the qualitative scoring system proposed by the consensus conference on Good Clinical Research Practice in Pharmacodynamic Studies of Neuromuscular Blocking Agents. ${ }^{19}$ Six variables were recorded: jaw relaxation, resistance to laryngoscope, vocal cord position, vocal cord movement, and patient response 
TABLE I Scoring conditions for tracheal intubation ${ }^{19}$

\begin{tabular}{llll}
\hline & \multicolumn{3}{c}{ Intubation conditions } \\
\cline { 2 - 3 } & \multicolumn{2}{l}{ Clinically acceptable } & $\begin{array}{l}\text { Clinically not } \\
\text { acceptable }\end{array}$ \\
\hline Variable & Excellent & Good & Poor \\
Laryngoscopy & - & - & - \\
Jaw relaxation & Relaxed & Not fully & Poor \\
$\begin{array}{l}\text { Resistance to } \\
\text { laryngoscope }\end{array}$ & None & Slight & Active \\
$\begin{array}{l}\text { Vocal cords } \\
\text { Position }\end{array}$ & - & - & - \\
$\begin{array}{l}\text { Movements } \\
\text { Reaction to tube } \\
\text { insertion or } \\
\text { cuff inflation }\end{array}$ & Abducted & Intermediate & Closed \\
$\begin{array}{l}\text { Movement of limbs } \\
\text { Coughing }\end{array}$ & None & Moving & Closing \\
& None & Slight & - \\
\hline
\end{tabular}

Intubation conditions: excellent $=$ all qualities are excellent; good $=$ all qualities are excellent or good; poor = the presence of a single quality listed under « poor ». Excellent and good intubation conditions are summarized as clinically acceptable intubation conditions. Reproduced, with permission from Viby-Mogensen J, Engbaek J, Eriksson LI, et al. Good clinical research practice (GCRP) in pharmacodynamic studies of neuromuscular blocking agents. Acta Anaesthesiol Scand 1996; 40: $59-74 .^{19}$

to intubation or cuff inflation (cough or movement). Each of these variables was rated as excellent, good, or poor. The criteria for assigning values to each variable are shown in Table I. Intubating conditions were considered excellent, if all criteria were scored as excellent, good, if all criteria were scored as either excellent or good, and poor, if a single criterion was scored as poor. Overall intubating conditions were judged clinically acceptable, if qualities were excellent or good, and were judged clinically not acceptable, if a single quality was poor.

The Cormack and Lehane score and the number of tracheal intubation attempts were recorded for each patient.

\section{Assessment of postoperative laryngeal symptoms and vo- cal cords injury}

Twenty-four and $48 \mathrm{hr}$ after the end of anesthesia, one of the authors, blinded to the patients' group assignment and unaware of the quality of tracheal intubation recorded, interviewed each patient in a standardized way. The patients were asked if they had experienced any hoarseness or sore throat since the operation. If sore throat or hoarseness persisted $48 \mathrm{hr}$ after surgery, a nasofibroscopic examination was performed by the same experienced ear-nose-throat physician who was blinded to the patient's group assignment.
One month after surgery, each patient was contacted to determine whether she had experienced a sore throat or any hoarseness during the $\mathbf{3 0}$ days following anesthesia, or, in the case of patients suffering from laryngeal symptoms $48 \mathrm{hr}$ after anesthesia, to determine the number of days it required for the symptoms to disappear. Any patient who suffered from sore throat or hoarseness during the 30 days following anesthesia underwent a nasofibroscopic examination.

\section{Statistical analysis}

The primary outcome of this study was the incidence of SLI, as assessed by nasofibroscopic examination, performed whenever the patient suffered from postoperative hoarseness and/or sore throat $48 \mathrm{hr}$ after surgery. Considering the incidence of laryngeal damage of $0.7 \%$ reported by Baillard et al. ${ }^{1}$ in a population of 565 patients, we assumed equivalence if the difference of the incidences between groups did not exceed $5 \%$ in perprotocol analysis, which corresponds to no significant clinical difference. ${ }^{20}$ Using Blackwelder's formula:

$$
n=\left(Z_{1-\alpha}+Z_{1-\beta}\right)^{2}[\pi s(1-\pi s)+\pi e(1-\pi e)] /(\Pi s-\pi e-\delta)^{2},
$$

where $\pi \mathrm{s}$ and $\pi \mathrm{e}$ are the true success proportions for standard and experimental therapy, $\mathrm{Z}_{1-\alpha}$ and $\mathrm{Z}_{1-\beta}$ are upper percentage points of the standard normal distribution, and $\delta$ the critical difference (equivalence margin), the sample size required to demonstrate equivalence between groups with $\delta=0.05, \alpha=0.05$, and $\beta=0.10$, was 48 patients per group. ${ }^{21}$ Because of the low expected incidence of SLI and because of potential protocol violations, we decided to include 130 patients to maximize the power of the study.

The secondary outcome was the frequency of acceptable intubating conditions. In patients having received NMBDs, for whom complete peripheral muscle relaxation was achieved, the reported rate of acceptable intubating conditions ranged from $92 \%$ to $98.9 \%{ }^{1,4}$ Considering a rate of $98 \%$ and $\delta=10 \%$, the number of patients required to perform an equivalence test with $\alpha=0.05$ and $\beta=0.10$ was 34 per group. ${ }^{21}$ Hence, the sample size allowed testing the equivalence of acceptable intubating conditions rates between both groups.

For these equivalence tests, the Blackwelder's test was used:

$$
\mathrm{Z}^{\prime}=(\operatorname{Ps}-\mathrm{Pn}-\delta) / \mathrm{SE},
$$

where $\mathrm{SE}=[\mathrm{Ps}(\mathrm{l}-\mathrm{Ps}) / \mathrm{ns}+\mathrm{Pe}(1-\mathrm{Pe}) / \mathrm{ne}]^{1 / 2}$ and $\mathrm{Ps}$ and $\mathrm{Pe}$ are the observed proportions, ne and ns are the numbers of patients in the two groups, and the 95\% 
TABLE II Patient characteristics

\begin{tabular}{lll}
\hline & $\begin{array}{l}\text { Cisatracurium } \\
(n=64)\end{array}$ & $\begin{array}{l}\text { Placebo } \\
(n=65)\end{array}$ \\
\hline Age $(\mathrm{yr})$ & $41.5 \pm 12.9$ & $40.7 \pm 15.2$ \\
Body mass index $\left(\mathrm{kg} \cdot \mathrm{m}^{-2}\right)$ & $24.6 \pm 5.4$ & $23.0 \pm 3.5$ \\
ASA class I / II $(n)$ & $46(72) / 18(28)$ & $48(74) / 17(26)$ \\
Mallampati class $1 / 2(n)$ & $44(69) / 20(31)$ & $43(66) / 22(34)$ \\
\hline
\end{tabular}

Data are presented as number $\mathrm{n}$ and $\%$, or mean \pm SD.

confidence intervals (95\% CI) of the difference of the rates of SLI and of acceptable intubating conditions between groups were calculated.

For analysis of the rates of acceptable intubating conditions and of SLI, per-protocol and intent-totreat analyses were performed. ${ }^{20}$ The clinically evaluable population included patients who completed the protocol of anesthesia, who were interviewed for the assessment of laryngeal symptoms, in a standardized way 24 and $48 \mathrm{hr}$ after anesthesia, and whose nasofibroscopic examination could be performed when necessary. All the patients included in this study defined the intent-to-treat population.

The conditions of tracheal intubation and the incidence of postoperative hoarseness, $24 \mathrm{hr}, 48 \mathrm{hr}$, and during the 30 days after anesthesia, were analysed using Chi-square or Fisher exact test, with Bonferroni adjustment for multiple comparisons when appropriate. Duration of anesthesia was compared using Student's $t$ test. Repeated measures of hemodynamic values were analyzed using two-way analysis of variance. For all tests, $P<0.05$ was considered significant.

\section{Results}

The study took place over eight months (from September 2006 to April 2007) in our department of anesthesia for gynecological surgery. One hundred and thirty female patients were enrolled in this study and were randomly allocated to either group Cisatracurium or group Placebo ( $n=65$ in each group). One patient in group Cisatracurium was excluded because of non-observance of the anesthetic protocol, leaving 129 clinically evaluable subjects in the per-protocol analysis $(n=65$ in group Placebo and $n=64$ in group Cisatracurium). As reported in Table II, the patient demographics were similar in the two groups. Anesthetic characteristics are shown in Table III. The distribution of endotracheal tubes of size 6.5 and $7 \mathrm{~mm}$ and the duration of anesthesia were similar in both groups.

For all patients, ventilation via facemask was easily achieved following induction of anesthesia. No patient experienced clinically significant rigidity, and
TABLE III Anesthetic characteristics

\begin{tabular}{llll}
\hline & $\begin{array}{l}\text { Cisatracurium } \\
(n=64)\end{array}$ & $\begin{array}{l}\text { Placebo } \\
(n=65)\end{array}$ & $P$ \\
\hline $\begin{array}{l}\text { Premedication } \\
\text { hydroxyzine } \\
\text { (patients, } n)\end{array}$ & $64(100)$ & $63(97.0)$ & 0.25 \\
$\begin{array}{l}\text { Premedication } \\
\text { alprazolam } \\
\text { (patients, } n)\end{array}$ & $57(89.0)$ & $55(84.6)$ & 0.31 \\
$\begin{array}{l}\text { Doses of } \\
\text { hydroxyzine }(\mathrm{mg})\end{array}$ & $51.6 \pm 14.7$ & $51.8 \pm 18.0$ & 0.89 \\
$\begin{array}{l}\text { Dose of } \\
\text { alprazolam }(\mathrm{mg})\end{array}$ & $0.38 \pm 0.22$ & $0.37 \pm 0.22$ & 0.84 \\
$\begin{array}{l}\text { Induction dose } \\
\text { of propofol }(\mathrm{mg})\end{array}$ & $2.50 \pm 0.06$ & $2.49 \pm 0.06$ & 0.39 \\
$\begin{array}{l}\text { Supplemental } \\
\text { boluses of propofol } \\
\text { remifentanil }(n)\end{array}$ & $3(4.7) / 2(3.1)$ & $10(15.4) /$ & $0.04 /$ \\
$\begin{array}{l}\text { Endotracheal tubes } \\
\text { of sizes } 6.5 \mathrm{~mm} /\end{array}$ & $19(29.7) /$ & $24(36.9) /$ & 0.25 \\
7 mm $(n)$ & $41(63.0)$ & \\
$\begin{array}{l}\text { Duration of } \\
\text { anesthesia }(\mathrm{min})\end{array}$ & $120 \pm 56$ & $105 \pm 50$ & 0.10 \\
\hline
\end{tabular}

Data are either number $n$ and $\%$, or mean \pm SD.

TABLE IV Quality of tracheal intubation in the clinically evaluable population

\begin{tabular}{llll}
\hline & $\begin{array}{l}\text { Cisatracurium } \\
(n=64)\end{array}$ & $\begin{array}{l}\text { Placebo } \\
(n=65)\end{array}$ & $P$ \\
\hline $\begin{array}{l}\text { Scoring conditions for } \\
\text { tracheal intubation }\end{array}$ & & & \\
$\begin{array}{l}\text { Clinically acceptable vs poor } \\
\quad \text { Clinically acceptable }\end{array}$ & $64(100)$ & $62(95.4)$ & \\
$\quad \begin{array}{l}\text { Poor } \\
\text { Excellent } v \text { good }\end{array}$ & $0(0)$ & $3(4.6)$ & \\
$\quad$ Excellent & $53(82.8)$ & $33(50.7)$ & 0.0003 \\
$\quad$ Good & $11(17.2)$ & $29(44.7)$ & \\
Cormack and Lehane score & & & 0.95 \\
1 & $38(59.4)$ & $37(57.0)$ & \\
2 & $25(39.0)$ & $27(41.5)$ & \\
3 & $1(1.6)$ & $1(1.5)$ & \\
Number of attempts & & & 0.96 \\
0 & $50(78.1)$ & $52(80.0)$ & \\
1 & $7(10.9)$ & $7(10.8)$ & \\
2 & $7(10.9)$ & $6(9.2)$ & \\
\hline
\end{tabular}

Data are presented as number $(n)$ and $\%$.

there were no intubation failures in either group. The quality of tracheal intubation in the clinically evaluable population is summarized in Table IV. In the clinically evaluable population, the rate of acceptable intubating conditions was $100 \%$ in group Cisatracurium and $95.4 \%$ in group Placebo $(P=0.12)$. Within acceptable intubating conditions, the rate of excellent conditions was significantly higher in group Cisatracurium compared to group Placebo $(P=0.0003)$. Notably, the 
Jaw relaxation

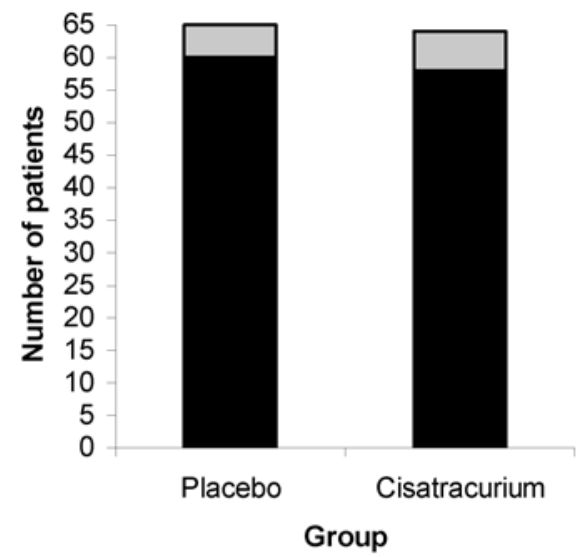

Resistance to laryngoscope

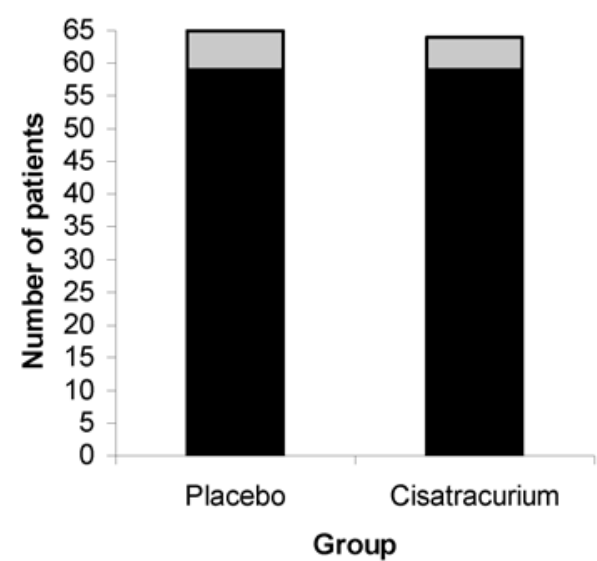

Vocal cords position

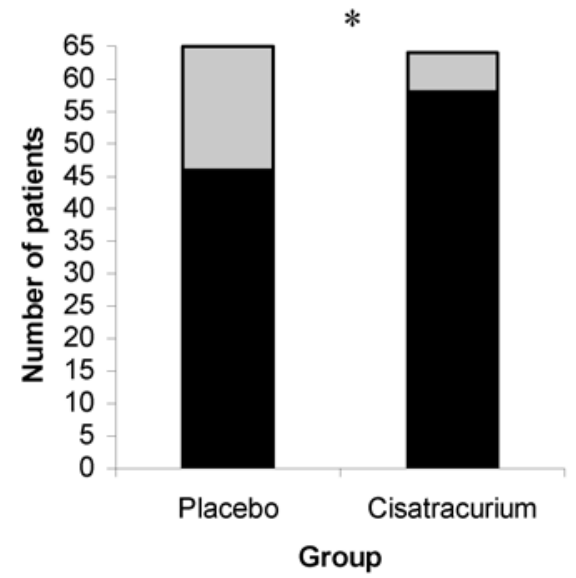

Movements of vocal cords

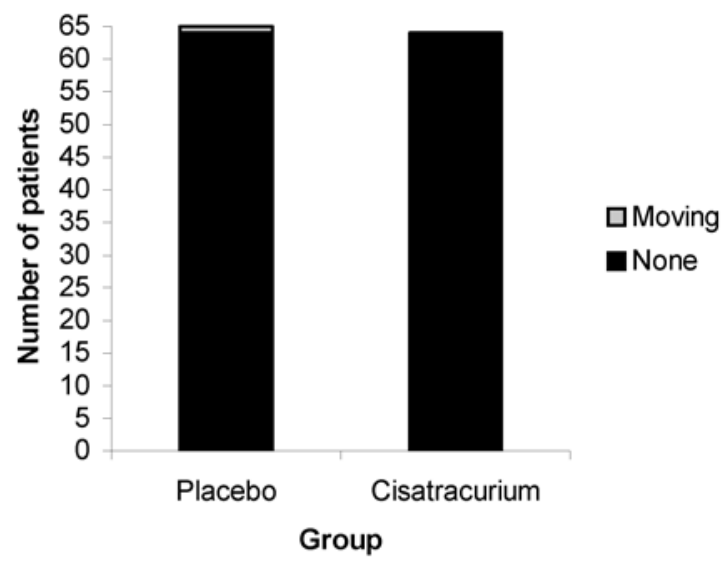

Movements of limbs

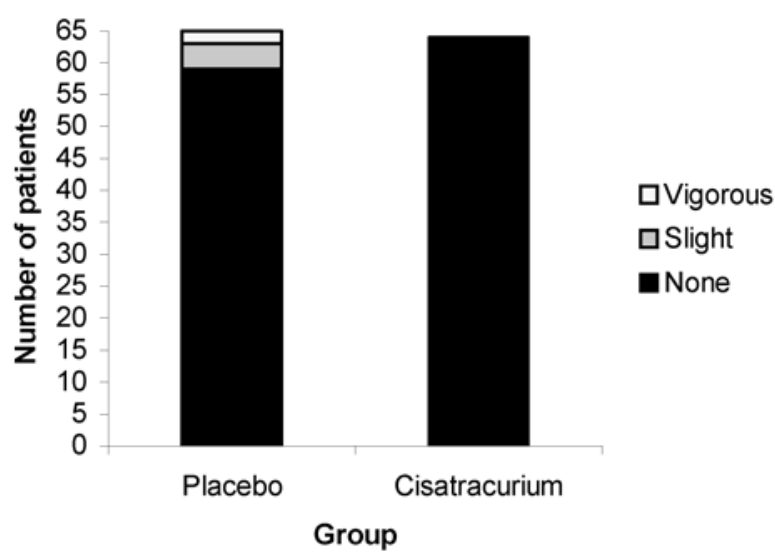

Coughing

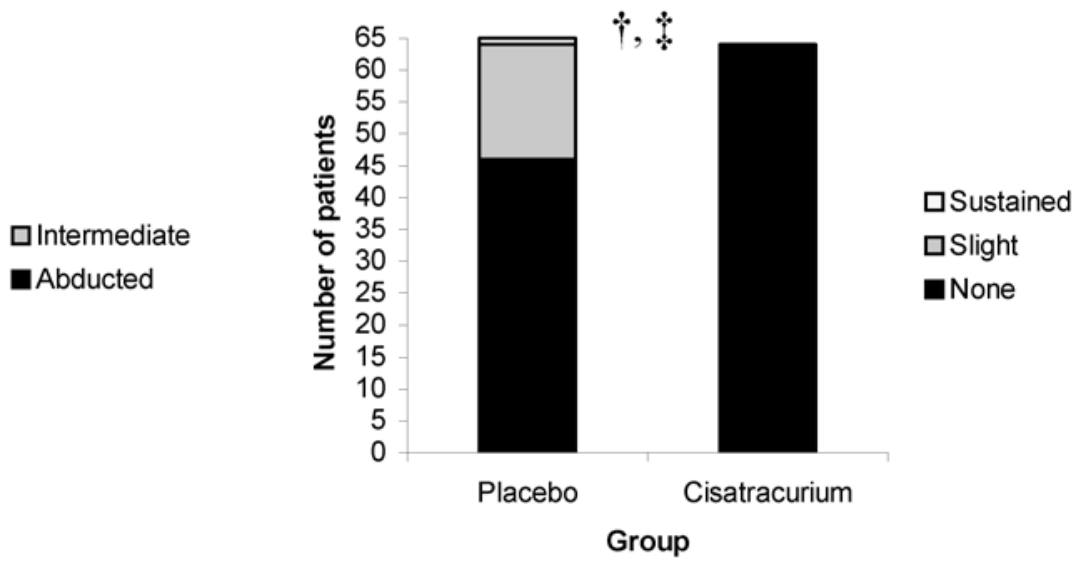

FIGURE 2 Distribution of patients according to quality of six criteria used for the assessment of tracheal intubating conditions (see text for criteria definitions). ${ }^{*} P=0.01$ between groups; $\uparrow P=0.001$ between groups, and $\ddagger P<0.0001$ between groups, for none $v s$ slight coughing. 
TABLE V Incidence of postoperative laryngeal symptoms and laryngeal injuries (SLI) in the clinically evaluable population

\begin{tabular}{llll}
\hline & $\begin{array}{l}\text { Cisatracurium } \\
(n=64)\end{array}$ & $\begin{array}{l}\text { Placebo } \\
(n=65)\end{array}$ & $P$ \\
\hline $\begin{array}{l}\text { Postoperative hoarseness } \\
\text { and sore throat }\end{array}$ & & & \\
$24 \mathrm{hr}$ after anesthesia & $17(26.5)$ & $\begin{array}{l}14(21.5) \\
4(6.1)\end{array}$ & 0.32 \\
$48 \mathrm{hr}$ after anesthesia & $5(7.8)$ & 0.50 \\
$\begin{array}{l}\text { Occurrence during the } \\
\begin{array}{l}30 \text { days after anesthesia } \\
\text { Laryngeal injuries at }\end{array}\end{array}$ & $1(0)$ & $0(0)$ & - \\
\begin{tabular}{l} 
nasofibroscopic examination \\
\hline
\end{tabular} & $1(1.6)$ & 0.75 \\
\hline
\end{tabular}

Data are presented as number $(n)$ and $\%$.

incidents of intermediate position of vocal cords and slight coughing were significantly increased in group Placebo (Figure 2), leading to significantly more frequent administration of supplemental boluses of remifentanil and/or propofol by the intubating anesthesiologist in this group of patients (Table III). The number of tracheal intubation attempts was similar in both groups (Table IV).

Per-protocol analysis showed that the 95\% CI of the difference of the rates of acceptable intubating conditions between groups ranged from $-0.44 \%$ to $9.8 \%$. This interval includes 0 and lies entirely within the range of equivalence of $-10 \%$ to $10 \%$ stated above. Therefore, the equivalence of acceptable intubating conditions rates between groups was confirmed. This result is corroborated by the Blackwelder's test of equivalence ( $z^{\prime}=-2.0$, i.e., $\left.P<0.05\right)$. Intention-totreat analysis showed that the $95 \%$ CI of the difference of the rates of acceptable intubating conditions between groups ranged from $-2.8 \%$ to $9.0 \%$.

As shown in Table $\mathrm{V}$, the incidence of postoperative hoarseness and sore throat, 24 and $48 \mathrm{hr}$ after anesthesia, was similar between groups. Sixty-three patients and 64 patients from group Placebo and group Cisatracurium, respectively, could be contacted 30 days after surgery. None of these patients experienced sore throat or hoarseness during the 30 days following surgery. Eight of nine patients suffering from laryngeal symptoms $48 \mathrm{hr}$ after anesthesia recovered in less than one week.

In each group, one patient suffered from laryngeal symptoms $48 \mathrm{hr}$ after anesthesia and had evidence of laryngeal damage at nasofibroscopic examination. As concerns the patient from group Cisatracurium, the trachea was easily intubated, and good intubating conditions were noted. All criteria were excellent, except for the intermediate position of the vocal cords. In this case, the duration of anesthesia was $190 \mathrm{~min}$. One day and $48 \mathrm{hr}$ after anesthesia, the patient suffered from sore throat, cough, and a decrease in voice inten- sity. Nasofibroscopic examination of the vocal cords showed a granuloma on the right vocal cord associated with sub-glottic edema. The symptoms persisted for ten days after anesthesia and did not recur during the following 20 days. Regarding the patient from group Placebo, the Cormack and Lehane score was 3, and two attempts were necessary to complete tracheal intubation, although criteria for tracheal intubation were judged as good (all criteria excellent, except for intermediate position of the vocal cords and slight movement of the diaphragm at cuff inflation). The duration of anesthesia was $100 \mathrm{~min}$. This patient suffered from sore throat, 24 and $48 \mathrm{hr}$ after anesthesia, without modification of the voice. Sub-glottic edema was found at nasofibroscopic examination. The symptoms persisted for five days after anesthesia and did not recur during the following 25 days.

Per-protocol analysis showed that the overall incidence of SLI was 1.6\% (one patient out of 64) in group Cisatracurium and $1.5 \%$ (one patient out of 65 ) in group Placebo $(P=0.75)$. The Blackwelder's test of equivalence gives $z^{\prime}=-2.34$, (i.e., $P<0.01$ ), and the $95 \% \mathrm{CI}$ of the difference of the rates ranged from $-4.1 \%$ to $4.1 \%$. This interval includes 0 and lies entirely within the range of equivalence of $-5 \%$ to $5 \%$. Therefore, the equivalence of the incidences of SLI, $48 \mathrm{hr}$ after anesthesia in both groups, was demonstrated in the clinically evaluable population. In the intent-to-treat population, the incidence of SLI was 3\% (two patients out of 65) in group Cisatracurium and $1.5 \%$ (one patient out of 65 ) in group Placebo, and the $95 \%$ CI of the difference of the rates ranged from $-3.5 \%$ to $6.7 \%$.

The mean onset of action of cisatracurium was $394 \mathrm{sec}(95 \% \mathrm{CI}: 359$ to $430 \mathrm{sec})$. Thus, for group Cisatracurium, the mean delay of the first attempt to intubate the trachea compared to the predefined time, $\mathrm{T}_{0}+270 \mathrm{sec}$, was $184 \mathrm{sec}(95 \% \mathrm{CI}: 149$ to $220 \mathrm{sec})$.

Hemodynamic responses are presented in Figure 3. In both groups, heart rate and systolic blood pressure decreased similarly after induction of anesthesia and did not return to respective baseline values after tracheal intubation. There were no significant differences between groups regarding the numbers of patients requiring ephedrine administration at induction of anesthesia [ $12(18.5 \%)$ in group Placebo vs $10(15.6 \%)$ in group Cisatracurium, $(P=0.42)]$, and regarding the median (interquartile range) dose of ephedrine administered $[9(6-12) \mathrm{mg}$ in group Placebo vs $13.5(6-18) \mathrm{mg}$ in group Cisatracurium, $(P=0.20)]$. No patient required atropine.

\section{Discussion}

Our study demonstrated that, according to naso- 


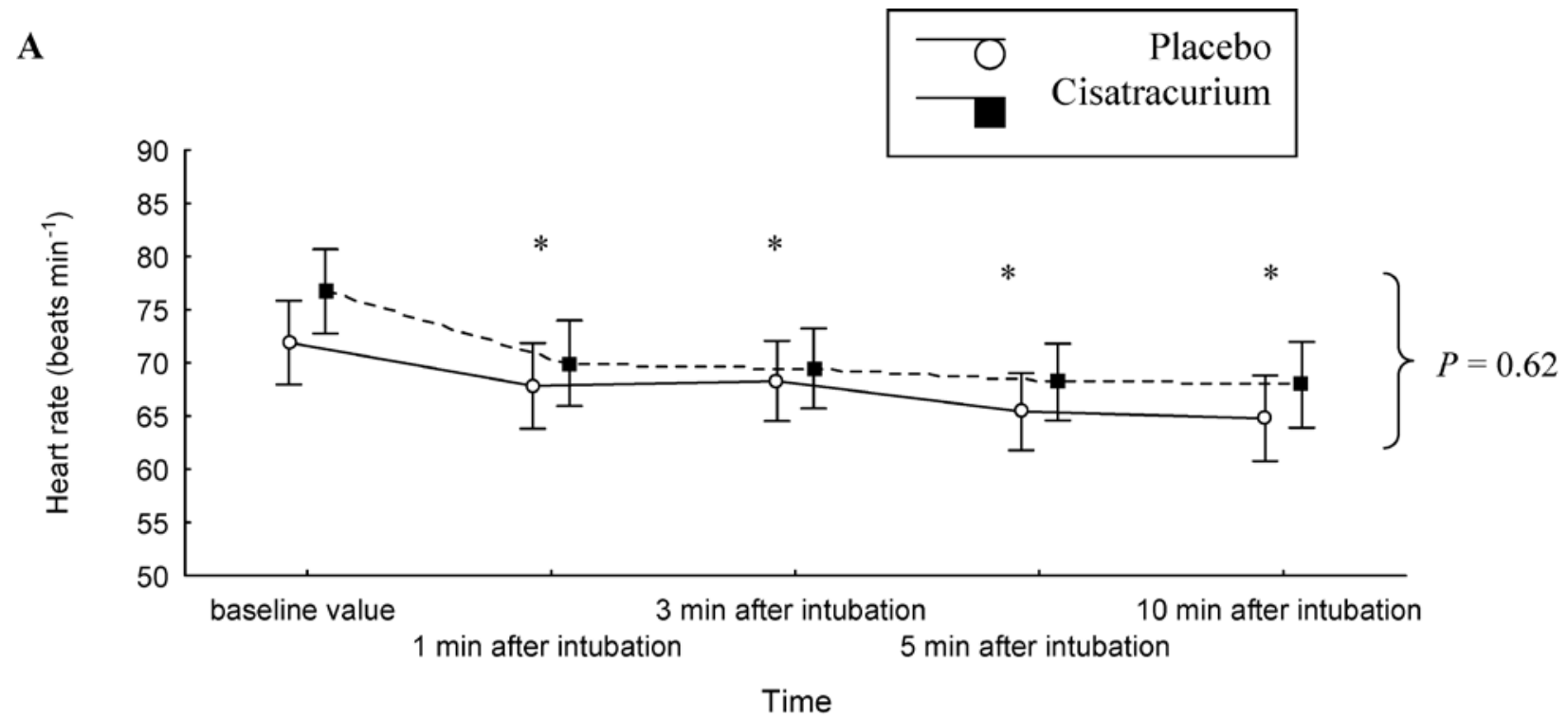

B

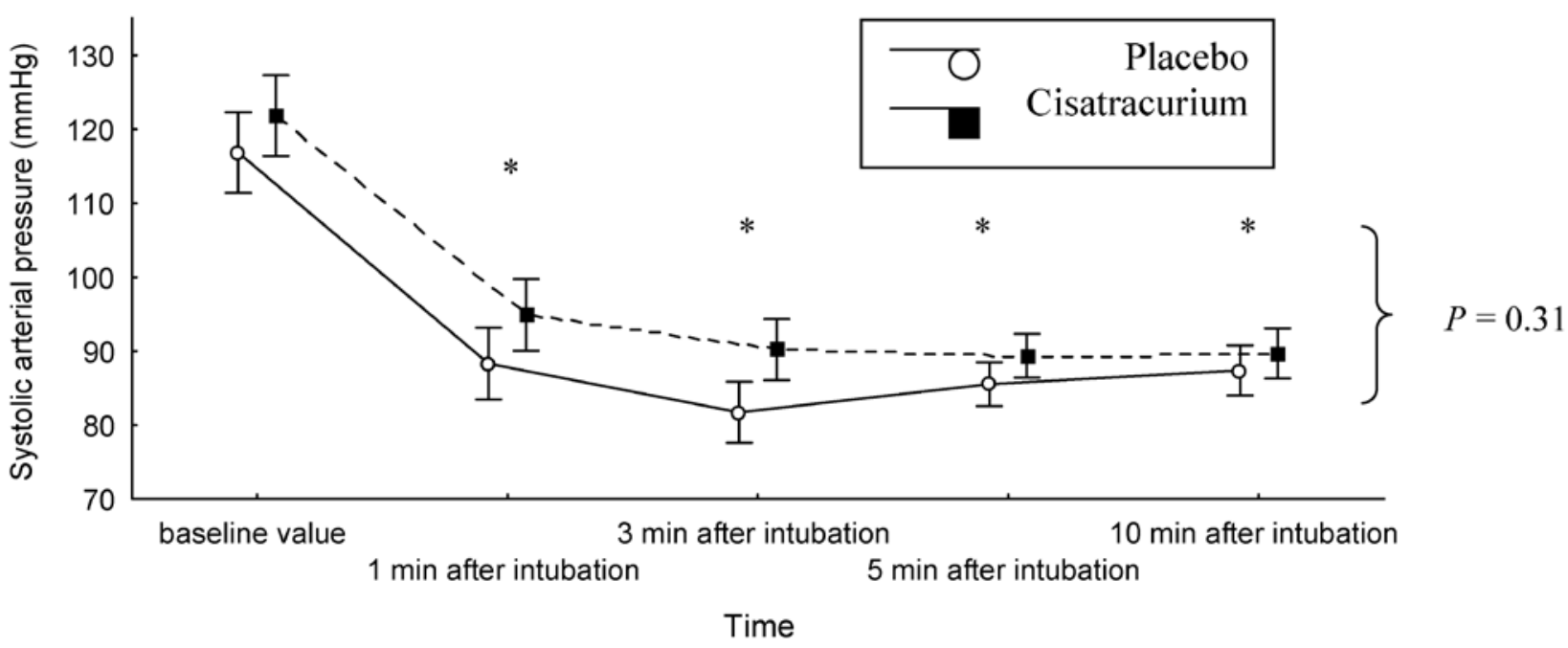

FIGURE 3 Mean hemodynamic responses. Data are presented as mean values and 95\% confidence intervals, and were compared by twoway analysis of variance. ${ }^{*} P<0.001$ vs baseline values. No significant between-group differences were observed.

fibroscopic examination, the rate of SLI occurring $48 \mathrm{hr}$ postoperatively, was equivalent, with or without adding cisatracurium to an anesthetic induction sequence using propofol $2.5 \mathrm{mg} \cdot \mathrm{kg}^{-1}$ iv and remifentanil $2 \mu \mathrm{g} \cdot \mathrm{kg}^{-1} i v$. These findings correlated with an equivalence rate of acceptable intubating conditions in over $95 \%$ of cases, including both good and excellent intubating conditions.

Intent-to-treat analysis showed that the $95 \% \mathrm{CI}$ of the difference of the incidences of SLI included 0 , 
but ranged from $-3.5 \%$ to $6.7 \%$, i.e., was larger than the equivalence margin $(\delta)$ we defined in the method section for the sample size calculation. However, our results remain of interest: first, in clinically evaluable patients, equivalence was demonstrated, as $95 \% \mathrm{CI}$ of the difference of the rates including 0 and was $<5 \%$. Second, the equivalence margin $(\delta=0.05)$ that we chose for the sample size calculation was narrow; it would have been clinically acceptable and relevant to have chosen a larger equivalence margin, up to $10 \%$, which is commonly used in equivalence studies. ${ }^{21}$ Intent-to-treat analysis of our results allowed us to conclude that the difference between the incidents of SLI in both groups included 0 and was less than 7\% with a confidence of $95 \%$. Accordingly, equivalence of the incidents of SLI between groups can reasonably be assumed.

The overall incidence of SLI at nasofibroscopic examination was low (less than 2\%) and comparable to that reported by Baillard et al. ${ }^{1}$ These results contrast with the much higher incidence of vocal cord sequelae, reaching $42 \%$ in non-relaxed patients as previously reported by Mencke et al. ${ }^{5}$ These authors performed systematic examination of the vocal cords, before and after each anesthetic. For our study, we considered it to be more relevant to assess the incidence of SLI, rather than to record the overall rate of laryngeal sequelae, including non-symptomatic injuries. Therefore, we chose to perform nasofibroscopic examination, only for those patients who were continuing to suffer from laryngeal symptoms $48 \mathrm{hr}$ to 30 days after anesthesia. This protocol discrepancy can explain, in part, the lower incidence of laryngeal damage which we report, compared to the observations of Mencke et al. ${ }^{5}$ Furthermore, the use of smaller tracheal tubes $(6.5$ and $7 \mathrm{~mm})$, compared to the larger tube sizes used in the study by Mencke et $a .^{5}$ ( $7.5 \mathrm{~mm}$ for women) may also have contributed to the incidence of laryngeal damage. The size of endotracheal tube contributes significantly to the occurrence of laryngeal morbidity. ${ }^{22}$ This factor may also explain our somewhat lower incidence of postoperative laryngeal symptoms, recorded $24 \mathrm{hr}$ after anesthesia, than reported by Combes et al. ${ }^{6}$ although female gender, gynecological surgery, and duration of intubation are well known risk factors for complaints of laryngeal symptoms after anesthesia. ${ }^{2,3}$

Finally, the selected doses of remifentanil and propofol ensured acceptable intubating conditions in more than $95 \%$ of patients. However, within acceptable conditions, the distribution of excellent and good conditions was unequal in the two groups. The use of cisatracurium significantly improved the intubating conditions, mainly by improving the position of vocal cords and by reducing the incidence of coughing at cuff inflation. Nevertheless, the incidence of acceptable (and of poor) intubating conditions remained equivalent in both groups. Hence, our findings highlight the issue of the need for excellent intubating conditions, in order to minimize the incidence of laryngeal complications due to tracheal intubation.

Cisatracurium was chosen as the NMBD for this study for two reasons. First, since the primary outcome of our study was the incidence of SLI, use of a depolarizing agent was avoided, because the role of succinylcholine in the etiology of postoperative sore throat and hoarseness remains unclear., ${ }^{2,3,23}$ Second, cisatracurium is reported to produce less histamine release and fewer allergic reactions compared to other nondepolarizing NMBDs, such as rocuronium, ${ }^{7,24}$ even though reports of anaphylactic reactions after cisatracurium administration were published since its introduction into clinical anesthesia. ${ }^{7}$

The mean onset of action of cisatracurium was $>$ six minutes, inducing a mean delay of three minutes of the first attempt to intubate the trachea compared to the patients in group Placebo. In order to have a reliable diagnosis of residual curarization and to guide reversal, we monitored the adductor pollicis muscle as a surrogate marker of the degree of cisatracurium block at the laryngeal muscle. Use of the adductor pollicis probably lengthened the waiting time for intubation, in comparison with a shorter hysteresis in observation time when the orbicularis oculi muscle is monitored. ${ }^{25}$

Our study has several limitations. First, only women were included, since this study was performed in a gynecological unit. However, female gender and gynecological surgery are well known factors of complaints of laryngeal symptoms after general anesthesia. ${ }^{2,3}$ It would be of interest to pursue further investigations with the inclusion of male patients. This study was performed on otherwise healthy and relatively young patients with no known risk-factors for difficult intubation. Accordingly, our results may not be applied to an older population, where the use of NMBDs might be required to optimize intubating conditions, or to a population in which hemodynamic tolerance with our induction protocol might be different. However, our study population may frequently be encountered in routine anesthesia; therefore, our results may be of interest in clinical practice.

In conclusion, the co-administration of remifentanil $2 \mu \mathrm{g} \cdot \mathrm{kg}^{-1}$ with propofol $2.5 \mathrm{mg} \cdot \mathrm{kg}^{-1}$, combined with the use of tracheal tube sizes of 6.5 or $7 \mathrm{~mm}$ 
in ASA I and II women, provided an equivalent, favourably low incidence of SLI in less than $5 \%$ of patients. This correlated with an equivalent rate of acceptable intubating conditions in more than 95\% of patients, with or without addition of cisatracurium during induction of anesthesia. The clinical tolerance of this induction protocol of anesthesia was good for the large majority of patients. Hence, our results raise the clinical question of the risks and benefits of the routine use of NMBDs for tracheal intubation. An adequate relaxant-free protocol of intravenous anesthetics, combined with optimization of the factors involved in the pathophysiology of airway damage related to anesthesia, allowed the avoidance of muscular relaxation for tracheal intubation. This approach may be recommended for ASA I and II elective surgical patients who do not require muscular relaxation for surgery. Further studies are required to assess the quality of intubating conditions and the hemodynamic tolerance of a muscle-relaxant free induction protocol in older ASA III-IV patients.

\section{References}

1 Baillard C, Adnet F, Borron SW, et al. Tracheal intubation in routine practice with and without muscular relaxation: an observational study. Eur J Anaesthesiol 2005; 22: 672-7.

2 Higgins PP, Chung F, Mezei G. Postoperative sore throat after ambulatory surgery. Br J Anaesth 2002; 88: 582-4.

3 Christensen AM, Willemoes-Larsen H, Lundby L, Jakobsen KB. Postoperative throat complaints after tracheal intubation. Br J Anaesth 1994; 73: 786-7.

4 Mencke T, Echternach M, Plinkert PK, et al. Does the timing of tracheal intubation based on neuromuscular monitoring decrease laryngeal injury? A randomized, prospective, controlled trial. Anesth Analg 2006; 102: 306-12.

5 Mencke T, Echternach M, Kleinschmidt S, et al. Laryngeal morbidity and quality of tracheal intubation. A randomized controlled trial. Anesthesiology 2003; 98: 1049-56.

6 Combes X, Andriamifidy L, Dufresne E, et al. Comparison of two induction regimens using or not using muscle relaxant: impact on postoperative upper airway discomfort. Br J Anaesth 2007; 99: 276-81.

7 Mertes PM, Laxenaire MC, Alla F; Groupe d'Études des Réactions Anaphylactoïdes Peranesthésiques. Anaphylactic and anaphylactoid reactions occurring during anesthesia in France in 1999-2000. Anesthesiology 2003; 99: 536-45.

8 Debaene B, Pland B, Dilly MP, Donati F. Residual paralysis in the PACU after a single intubating dose of nondepolarizing muscle relaxant with an intermediate duration of action. Anesthesiology 2003; 98: 1042-8.

9 Sandin RH, Enlund G, Samuelsson P, Lennmarken C. Awareness during anaesthesia: a prospective case study. Lancet 2000; 355: 707-11.

10 McNeil IA, Culbert B, Russell I. Comparison of intubating conditions following propofol and succinylcholine with propofol and remifentanil 2 micrograms $\mathrm{kg}^{-1}$ or 4 micrograms $\mathrm{kg}^{-1}$. Br J Anaesth 2000; 85: 623-5.

11 Stevens JB, Wheatley L. Tracheal intubation in ambulatory surgery patients: using remifentanil and propofol without muscle relaxants. Anesth Analg 1998; 86: 45-9.

12 Grant S, Noble S, Woods A, Murdoch J, Davidson $A$. Assessment of intubating conditions in adults after induction with propofol and varying doses of remifentanil. Br J Anaesth 1998; 81: 540-3.

13 Durmus M, Ender G, Kadir BA, Nurcin G, Erdogan $O$, Ersoy $M O$. Remifentanil with thiopental for tracheal intubation without muscle relaxants. Anesth Analg 2003; 96: 1336-9.

14 Erhan E, Ugur G, Alper I, Gunusen I, Ozyar B. Tracheal intubation without muscle relaxants: remifentanil or alfentanil in combination with propofol. Eur J Anaesthesiol 2003; 20: 37-43.

15 Alexander R, Booth J, Olufolabi AJ, El-Moalem HE, Glass PS. Comparison of remifentanil with alfentanil or suxamethonium following propofol anaesthesia for tracheal intubation. Anaesthesia 1999; 54: 1032-6.

16 Scheller MS, Zornow MH, Saidman LJ. Tracheal intubation without the use of muscle relaxants: a technique using propofol and varying doses of alfentanil. Anesth Analg 1992; 75: 788-93.

17 Shiga T, Wajima Z, Inoue T, Sakamoto A. Predicting difficult intubation in apparently normal patients: a meta-analysis of bedside screening test performance. Anesthesiology 2005; 103: 429-37.

18 Capron F, Alla F, Hottier C, Meistelman C, FuchsBuder T. Can acceleromyography detect low levels of residual paralysis? A probability approach to detect a mechanomyographic train-of-four ratio of 0.9 . Anesthesiology 2004; 100: 1119-24.

19 Viby-Mogensen J, Engbaek J, Eriksson LI, et al. Good clinical research practice (GCRP) in pharmacodynamic studies of neuromuscular blocking agents. Acta Anaesthesiol Scand 1996; 40: 59-74.

20 Le Henanff A, Giraudeau B, Baron G, Ravand P. Quality of reporting of noninferiority and equivalence randomized trials. JAMA 2006; 295: 1147-51.

21 Blackwelder WC. "Proving the null hypothesis" in clinical trials. Control Clin Trials 1982; 3: 345-53. 
22 Stout DM, Bishop MJ, Dwersteg JF, Cullen BF.

Correlation of endotracheal tube size with sore throat and hoarseness following general anesthesia. Anesthesiology 1987; 67: 419-21.

23 Capan LM, Bruce DL, Patel KP, Turndorf $H$. Succinylcholine-induced postoperative sore throat. Anesthesiology 1983; 59: 202-6.

24 Doenicke A, Soukup J, Hoernecke R, Moss J. The lack of histamine release with cisatracurium: a double-blind comparison with vecuronium. Anesth Analg 1997; 84: 623-8.

25 Debaene B, Beaussier M, Meistelman C, Donati F, Lienhart $A$. Monitoring the onset of neuromuscular block at the orbicularis oculi can predict good intubating conditions during atracurium-induced neuromuscular block. Anesth Analg 1995; 80: 360-3.

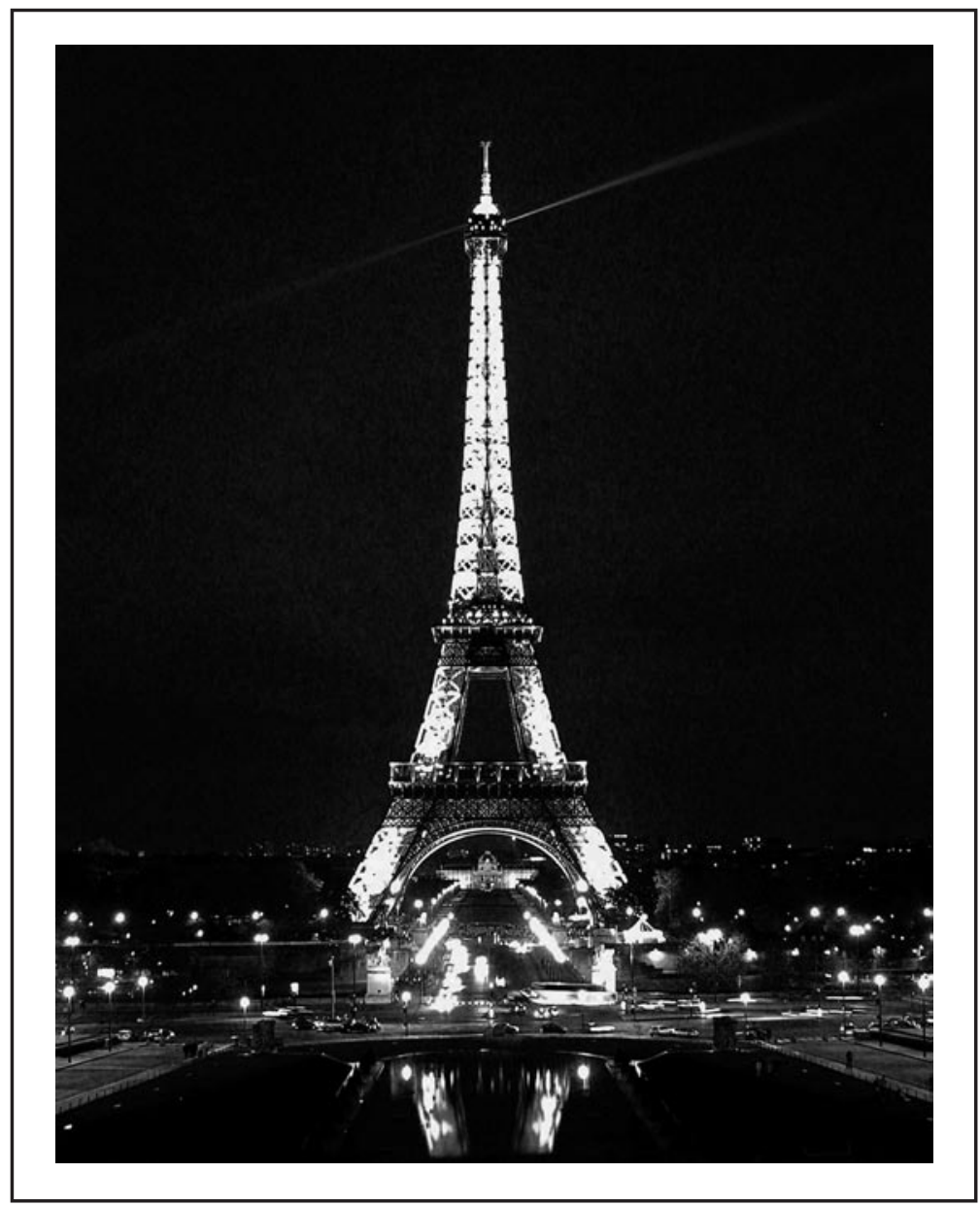

Eiffel Tower - Paris, France 